\title{
Prohibicionismo suave para abordar el trabajo sexual callejero: ordenanzas cívicas y ley mordaza ${ }^{1}$
}

\author{
Soft prohibitionism to face street sex work: Civic ordinances and the Gag \\ Act
}

\author{
Carolina Villacampa Estiarte \\ Universitat de Lleida \\ carolina.villacampa@udl.cat \\ 0000-0002-1791-8788
}

\section{Resumen}

En España el ejercicio del trabajo sexual no se encuentra regulado. Aunque en el plano político ha triunfado el modelo neoabolicionista que, identificando trata de seres humanos y prostitución, sanciona conductas de explotación de la prostitución y de consumo de servicios sexuales, normativamente dicho modelo se ha adoptado solo en apariencia. El Derecho penal sanciona la determinación a la prostitución y la explotación de la prostitución ajena, aun con el consentimiento de la persona prostituida incluso si esta es mayor de edad, junto a la facilitación de la prostitución de menores de edad y personas discapacitadas necesitadas de especial protección. Sanciona además la compra de servicios de naturaleza sexual y el consumo de pornografía únicamente cuando son prestados por personas menores o discapacitadas. Sin embargo, con el nuevo milenio se ha impuesto un modelo prohibicionista suave de la mano de la aprobación masiva de ordenanzas cívicas que sancionan el ofrecimiento de servicios sexuales en la calle, imponiendo multas tanto a las trabajadoras sexuales como a quienes efectivamente sufren explotación sexual. A ellas se une la Ley Mordaza, que acaba asimismo sancionando a las trabajadoras sexuales que ofrecen sus servicios en la vía pública. La aplicación de estas normas está suponiendo la criminalización del trabajo sexual callejero, sin ofrecer alternativas legales ni abordar adecuadamente la explotación sexual.

\footnotetext{
${ }^{1}$ Este trabajo ha sido realizado en el marco del proyecto RTI2018-094686-B-C21, "Hacia una Ley integral contra la trata de seres humanos y la esclavitud” (Ministerio de Ciencia, Innovación y Universidades).
} 
Palabras clave: ordenanzas cívicas, Ley Mordaza, prohibicionismo suave, trabajo sexual.

\begin{abstract}
Sex work is not regulated in Spain. Although the neo-abolitionist model, which identifies human trafficking and prostitution and punishes exploitative behaviour in prostitution and the consumption of sexual services, has triumphed at the political level, at a normative level it only appears to have been adopted. Criminal law punishes the coercion to and the exploitation of others' prostitution, even with the consent of the prostituted person and even if that person is of age, along with the facilitation of the prostitution of minors and disabled persons in need of special protection. The purchase of services of a sexual nature and the consumption of pornography are only punished when provided by minors or disabled persons. In the new millennial, however, the widespread promulgation of civic ordinances has meant the adoption of a soft prohibitionist model. Most of these ordinances sanction the offering of sexual services in the street, imposing fines on sex workers and sexually exploited persons alike. In addition, sex workers who offer their services on the street also end up being sanctioned under the Gag Act. The result is the criminalization of street sex work, without adequately addressing cases of sexual exploitation and without offering viable legal alternatives to the practice of sex work.
\end{abstract}

Key words: Civic ordinances, Gag Act, soft prohibitionism, sex work. 


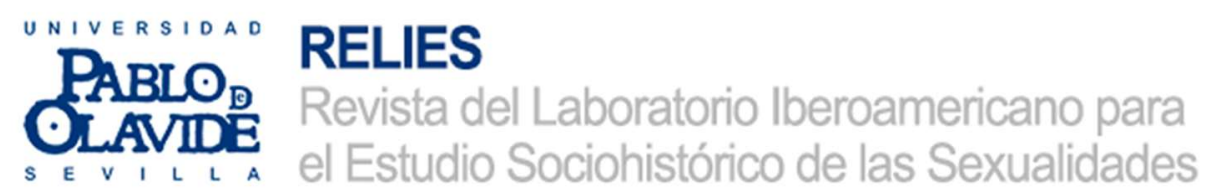

\section{Cuestiones introductorias}

Los modelos de abordaje normativo de la prostitución adoptados desde mediados del s. XIX se identifican con el reglamentarismo, el abolicionismo, el prohibicionismo $y$, en último término, el conocido como modelo regulacionista, de legalización, laboral, de derechos o de disminución del daño (por todos, Maqueda, 2009; Villacampa, 2012; Sobrino, 2018).

Superadas teóricamente las aproximaciones propias de los modelos indicados basados en la culpabilización de la mujer prostituida -reglamentarismo y prohibicionismo-, los dos modelos jurídicos actualmente en pugna en occidente por gestionar la aproximación normativa a la prostitución son el abolicionismo y el modelo de la legalización. Tanto el reglamentarismo, primera de las formas de aproximación que buscó sobre todo la zonificación del ejercicio del trabajo sexual para evitar la expansión de las enfermedades infecciosas indebidamente atribuida a las prostitutas, cuanto el prohicionismo, que trató de erradicar la prostitución sancionando a las propias trabajadoras sexuales, pueden considerarse formalmente superados. Esto aun cuando en algunos países, así algunos estados en USA, se sigue todavía sancionando penalmente a las trabajadoras sexuales. Actualmente son el abolicionismo y el modelo de la legalización, que en ningún caso culpan a las mujeres que ejercen la prostitución de su existencia, sino que buscan su dignificación desde diversas perspectivas, los asumidos en los distintos estados occidentales para sentar las bases sobre las que sedimentar la correspondiente política legislativa en esta materia.

Como es sabido, el abolicionismo, surgido en la Inglaterra del s. XIX a impulso del movimiento feminista, consideró que la dignificación de estas personas pasaba por la erradicación de la prostitución, lo que debía hacerse a través de la sanción de los reales culpables, quienes explotan o se benefician de esta actividad. Partiendo de su base humanista y de la estrecha relación entre la prostitución y la trata de esclavos, este movimiento asumió su denominación precisamente por el paralelismo establecido entre el abolicionismo de la esclavitud y el de la trata de blancas primero, así como con el de trata de seres humanos después. En efecto, en su versión contemporánea conocida como neoabolicionismo- este movimiento ha conducido a la identificación de la prostitución con la trata de seres humanos, de manera que el instrumento primordial para conseguir la ansiada abolición de dicha realidad pasa por la sanción fundamentalmente de quienes demandan la prestación de servicios sexuales (Ekberg, 2004), los clientes, como hace actualmente el país europeo abanderado en la implementación de este tipo de política, Suecia. De ahí que se lo designe como modelo sueco o nórdico.

Por el contrario, el modelo regulacionista o de la legalización busca también la dignificación del ejercicio del trabajo sexual, aunque sin pretender que la única forma de hacerlo sea a través de la abolición de dicha práctica. Se originó en los años 80 del pasado siglo, cuando las organizaciones de trabajadoras sexuales comenzaron a hacerse oír reclamando el reconocimiento de derechos laborales y prestaciones de carácter social. No pretende acabar con la prostitución, sino intentar que se desarrolle en las mejores condiciones jurídicas y sociales posibles para quienes la ejercen. Persigue otorgar a las trabajadoras sexuales, como al resto de trabajadores, derechos fundamentalmente de contenido social, lo que hace que sea el asumido por países en que se ha legalizado con condiciones el ejercicio de la prostitución, como Holanda o Alemania.

De forma paralela al mantenimiento preferente de los dos modelos antedichos, en algunos países europeos, como España e Italia, la gestión normativa de la prostitución, en concreto de la que se 
ejerce en la calle, se ha cruzado con el abordaje normativo de los usos permitidos en los espacios públicos. Ya sea partiendo de la afirmada necesidad de proteger la seguridad ciudadana entendida en sentido amplio -identificada con la protección de las personas y bienes y con el mantenimiento de la tranquilidad de los ciudadanos, como hace el art. 1 de la Ley Orgánica 4/2015, de 30 de marzo, de Protección de la Seguridad Ciudadana, en delante LO 4/2015 o Ley Mordaza-, ya de salvaguardar la convivencia ciudadana o cívica, se han articulado una serie de instrumentos normativos de carácter administrativo que obedecen al mantenimiento de un determinado estándar de seguridad. Se trata del recurso a medidas administrativas sancionatorias de carácter preventivo que tienen por objeto apartar de los espacios públicos a quienes se consideran amenazas potenciales a la seguridad en estos. Tales reglamentaciones han conducido a que determinados individuos, los "failed citizens" o los "no ciudadanos", sean segregados y controlados (Bickford, 2000; Wacquant, 2009; Beckett y Herbert, 2010). En España, hasta la aprobación de la Ley Mordaza, ha sido sobre todo por medio de la adopción de ordenanzas municipales como se habían venido articulando estas medidas de control del espacio público en aras a la supuesta protección de la convivencia ciudadana que han contribuido a segregar a diversos grupos de ciudadanos, entre los que se encuentran las trabajadoras sexuales de calle.

Tras la aprobación de la LO 4/2015 este papel desempeñado en primer término por las referidas normativas municipales ha acabado siendo asumido a nivel estatal con motivo de la protección de la seguridad ciudadana. Como se expondrá en este trabajo, tanto las ordenanzas cívicas aprobadas en la mayor parte de municipios españoles durante los primeros años 2000 como después la Ley Mordaza han supuesto la adopción de un modelo prohibicionista suave en materia de prostitución que ha contribuido a invisibilizar a las trabajadoras sexuales y que, sin haber conseguido una reducción de la oferta de trabajo sexual, las ha expulsado del espacio público (Arella, Fernández, Nicolás y Vartabedian, 2007; Vartabedian, 2011 y 2013; Villacampa y Torres, 2013; Villacampa, 2015; Maqueda, 2015 y 2017; Barcons, 2018; Bodelón y Becerra, 2018). Sin embargo, antes de analizar estas normativas y cómo han afectado al ejercicio del trabajo sexual callejero, veamos cuál es la forma de aproximación normativa a la prostitución adoptada a nivel internacional y regional europeo, descendiendo después a analizar la situación normativa en España. Se observará cómo la misma adolece de un relevante vacío regulativo que ha conducido a que fuesen los ayuntamientos quienes acabasen marcando la política normativa en la materia a través de las denominadas ordenanzas cívicas.

\section{Aproximación normativa internacional a la prostitución}

En el ámbito internacional, la adopción de posiciones abolicionistas para la gestión de la prostitución fue la triunfante en los inicios de la lucha internacional contra esta realidad. Esto se hizo evidente en la Convención de Naciones Unidas para la represión de la trata de personas y de la explotación de la prostitución ajena de 1949, que se ha identificado con el triunfo del abolicionismo (Maqueda, 2009), puesto que su tenor se hallaba fuertemente influenciado por movimientos que asumieron esa aproximación, identificando la trata de blancas con la prostitución. El texto impone la obligación de sancionar la compra de servicios sexuales, la explotación de la prostitución aun con la anuencia de la persona prostituida, la tercería locativa y el mantenimiento, la administración, el sostenimiento o la financiación de una casa de prostitución, con independencia de las condiciones en que tal actividad se ejerza.

Para el neoabolicionismo, la primigenia identificación de la trata de blancas con la prostitución se sustituyó por la equivalencia absoluta entre esta última y la trata de seres humanos. Nuevamente, pues, cualesquiera que fueran las condiciones en que la prostitución se ejerciese, para esta corriente de pensamiento ambas realidades se solapan, sin admitirse distinciones entre el ejercicio libre o 
escasamente condicionado del trabajo sexual y la imposición de una situación de prostitución por un tratante.

Pese a sus intentos y a ser muy hegemónico en la regulación interna norteamericana de la trata de seres humanos, el lobby de los neoabolicionistas, representado por la International Human Rights Network, no consiguió imponer sus tesis en las discusiones sobre la definición que debía darse a la trata de seres humanos para explotación sexual en el Protocolo para prevenir, reprimir y sancionar la trata de personas que complementa la Convención de Naciones Unidas contra la delincuencia organizada transnacional (Villacampa, 2011). Este grupo, por contraposición a la tesis sostenida por la Coalición Human Rights Caucus, pretendía, sobre la base de la ausencia de distinción entre formas de prostitución voluntaria y forzada, que se identificaran enteramente prostitución y trata, de manera que en la trata de personas para explotación sexual no fuera necesario el empleo de los medios comisivos que integran la trata coactiva, la abusiva y la fraudulenta y que sí deberían continuarse requiriendo en las demás manifestaciones de este fenómeno. La definición de la trata de seres humanos contenida en el art. 3 del Protocolo, al exigir la concurrencia de medios comisivos en todas sus formas, incluida la sexual, refleja así el compromiso adquirido para poner fin al debate sobre la prostitución que acabó focalizando gran parte de las discusiones producidas en relación con los contenidos de dicho Protocolo, e impide afirmar que en este documento se asumiese una posición claramente abolicionista (Villacampa, 2012).

Semejante posición de equidistancia respecto de las posiciones neoabolicionistas, por un lado, y las orientadas a la protección de los derechos humanos de las personas que prestan sus servicios en la industria sexual, por otro, es la mantenida tanto por el Convenio del Consejo de Europa sobre la lucha contra la trata de seres humanos de 2005 como por la Directiva 2011/36/UE, de 5 de abril de 2011, relativa a la prevención y la lucha contra la trata de seres humanos. En ambos documentos se reconoce la relación existente entre la trata de seres humanos para explotación sexual y la prostitución, pero sin llegarse a identificar ambas realidades, abordándose este fenómeno desde la perspectiva de los derechos humanos y exigiéndose consecuentemente para la trata de seres humanos con fines de explotación sexual los mismos medios comisivos que para el resto de manifestaciones del fenómeno.

Sin embargo, la neutralidad instaurada a nivel internacional con el Protocolo de Palermo se ha visto abandonada en los últimos años en el ámbito regional europeo, en que en la última década se están adoptando aproximaciones normativas a la prostitución claramente abolicionistas. Siguiendo la estela del modelo sueco o nórdico, que condujo a la criminalización de la compra de servicios sexuales en el Código penal sueco en 1999 a través de la aprobación de la Sex Purchase Act, después exportado a países como Noruega, Islandia, Reino Unido o Francia, entre otros, el Parlamento Europeo adoptó la Resolución de 26 de febrero de 2014, sobre explotación sexual y prostitución y su impacto en la igualdad de género. Asumiendo la misma base ideológica que la ley sueca, el Parlamento europeo considera la prostitución como una manifestación de la desigualdad de género. Pese a que se refiere a la diferencia entre prostitución voluntaria y forzada y a las dos formas contemporáneas de enfoque de dicha realidad -abolicionista y regulacionista-, concluye con la práctica identificación de cualquier forma de prostitución con la trata de seres humanos, con la necesidad de atacar penalmente a la demanda de servicios sexuales y mostrándose claramente contrario a la legalización del trabajo sexual. 


\section{Situación normativa en España}

El ejercicio del trabajo sexual permanece en nuestro país en el mismo limbo jurídico extrapenal en que se halla anclado desde hace años, pues no se sanciona penalmente el ofrecimiento voluntario de servicios sexuales o su consumo -como sucede en Suecia-, pero tampoco se regula la prestación de estos servicios a nivel administrativo, laboral o fiscal, como sucede en Holanda o Alemania. El ordenamiento español sigue así manteniendo una hipócrita indefinición que ha impedido a las trabajadoras sexuales darse de alta en el sistema nacional de seguridad social como tales por cuenta propia o ajena, aunque la relación de alterne se haya considerado jurisprudencialmente relación laboral; no así, salvo alguna contada excepción, la relación de prostitución.

Más allá de las referidas ordenanzas cívicas y de la Ley Mordaza, las únicas regulaciones al margen de las disposiciones penales que se han adoptado en España en materia de prostitución han tenido que ver con la zonificación de la misma y con las condiciones que deben cumplir los locales en los que se ejerce, conforme marca la tradición reglamentarista. Ante las tentativas fallidas de algunas Comunidades Autónomas de legalizar la prestación de servicios sexuales en determinadas condiciones, su actividad normadora se ha limitado a establecer las condiciones que deben cumplir los locales en que se ejerce la prostitución.

Desde el punto de vista jurídico-penal, España parece haber asumido el modelo abolicionista, si bien lo ha conseguido solo parcialmente, aunque en el plano político su asunción resulta indiscutible. Basta para cerciorarse de esto último una lectura del informe de la Ponencia sobre prostitución en España, adoptado por la Comisión Mixta de los Derechos de la Mujer y de la Igualdad de Oportunidades de 2007. También del Plan integral de lucha contra la trata de seres humanos con fines de explotación sexual aprobado por el gobierno socialista de Rodríguez Zapatero o del Plan integral de lucha contra la trata de mujeres y niñas con fines de explotación sexual 2015-2018, aprobado por el posterior gobierno popular. Todos estos documentos identifican plenamente la prostitución con la trata de seres humanos.

No parece que la llegada al poder del primer gobierno socialista de Pedro Sánchez ni del actual gobierno de coalición PSOE-Unidas Podemos vaya a cambiar excesivamente las cosas en el plano político. La aproximación abolicionista a la prostitución sigue así constituyendo el discurso dominante en el plano político. El Plan integral de lucha contra la trata de mujeres y niñas de 2015 sigue vigente y se anunció la aprobación de una ley integral de protección de las víctimas de trata para explotación sexual en 2018 que asume claramente el modelo sueco, pero que quedó en borrador, sin llegar a entrar en tramitación parlamentaria ni al final de la XII ni durante la efímera XIII legislatura. Además, en las medidas a adoptar en el marco del Pacto de Estado contra la violencia de género a desplegar en el quinquenio 2018-2022 puede observarse cómo se siguen identificando trata de seres humanos y prostitución (Delegación del Gobierno para la Violencia de Género, 2019), especialmente cuando se aborda la necesidad de aprobar una ley integral para proteger a las mujeres víctimas de trata de seres humanos para explotación sexual. Si acaso, el actual escenario político puede suponer que acabe culminando la asunción del modelo abolicionista también en el ámbito jurídico-penal, como después se mostrará.

Entrando pues a exponer brevemente cuál es la realidad en el plano jurídico-penal, la situación normativa podría tildarse de asunción todavía incompleta del modelo abolicionista. En el Código Penal español, la prostitución de adultos se sanciona penalmente cuando se determina a una persona mayor de edad a mantenerse en la prostitución si concurren determinados medios comisivos que convierten la determinación a la prostitución en coactiva, fraudulenta o abusiva (art. 187 CP). La inducción, el favorecimiento y la facilitación de la prostitución de menores y personas discapacitadas necesitadas de especial protección constituye delito en todo caso (art. $188 \mathrm{CP}$ ). Junto a tales conductas, el consumo de diversos servicios sexuales -los prestados por personas 
prostituidas, el acceso a espectáculos pornográficos y la pornografía- se sanciona penalmente solo cuando la persona que los presta es menor o persona discapacitada necesitada de especial protección.

También únicamente respecto de estos sujetos pasivos especialmente vulnerables se sancionan con carácter general las conductas de explotación de la prostitución, o las de explotación consistentes en su empleo en espectáculos exhibicionistas o pornográficos o en su uso para elaborar material pornográfico. Entre las conductas de explotación de la prostitución se halla el proxenetismo que, a diferencia del resto, ya desde la reforma penal de 2003 se sanciona aun sin ser coercitivo también en relación con la prostitución de adultos, dado que el entonces art. 188.1 in fine CP incriminó la conducta consistente en lucrarse con la explotación de la prostitución de otra persona aun con el consentimiento de la misma, aproximándose con esto a las tesis abolicionistas. No obstante, la interpretación restrictiva de esta conducta que se ha ido consolidando ha conducido a frustrar las aspiraciones del legislador de 2003, pues no se ha aplicado a todos los que se lucran de la prostitución de otro cualesquiera que sean las condiciones en que esta persona la ejerza. Se han asumido tanto jurisprudencialmente (sentencia del Tribunal Supremo 445/2008) como en el ámbito académico (Maqueda, 2009; Villacampa, 2012; Llobet, 2017) exégesis restrictivas en virtud de las cuales el tipo se ha aplicado solo cuando alguien se lucra explotando la prostitución de un adulto que no la ejerce libremente o cuando se imponen condiciones de prestación abusivas aunque hayan sido aceptadas por la persona prostituida.

La piedra de toque para mantener la circunscrita aplicación de este tipo ha sido la interpretación restrictiva del término típico "explotación", que fue modificado en 2015 previsiblemente para acabar con su limitado recorrido, como se deduce de la propia exposición de motivos de la Ley Orgánica 1/2015, que operó la modificación. Esta reforma, además de trasladar las formas de intervención típica en la prostitución de adultos del art. 188 al 187 CP, modificó la pena del delito de proxenetismo no coercitivo, rebajándola y permitiendo con ello justificar interpretaciones más laxas del tipo. Junto a esto, tras diversos vaivenes durante la tramitación de la norma, la redacción finalmente aprobada de esta conducta típica -art. 187.1, 2ㅇofo, CP- puede apuntalar la aplicación amplia de las conductas consistentes en obtener lucro explotando la prostitución ajena. Esto porque entre los casos que se consideran como explotación se incluyen, junto a aquellos que serían equiparables a supuestos de explotación laboral -imponer para el ejercicio de la prostitución condiciones gravosas, desproporcionadas o abusivas- como se venía haciendo hasta 2015, los supuestos de explotación basados en la vulnerabilidad de la víctima que se conciben en términos muy amplios. Basta para apreciarla que la víctima se encuentre en cualquier situación de vulnerabilidad personal o económica, aun cuando le quepan otras alternativas de actuación.

Solo el tiempo dirá si la interpretación jurisprudencial restrictiva relativa al delito de proxenetismo no coercitivo mantenida hasta 2015 logra mantenerse. De momento, lo que parece puede constatarse es que esta modificación condujo a que en 2016 no hubiese ni una sola causa por este delito, por lo que la Fiscalía General del Estado tildó la reforma de ineficaz en su memoria anual. Con todo, las opciones restrictivas de este tipo delictivo se tornan cada vez más difíciles de sostener. Se va adoptando más claramente el modelo abolicionista, aun cuando no hayamos todavía asumido el modelo sueco de sanción al cliente. Debe tenerse en cuenta que no solo el delito de proxenetismo no coercitivo puede servir para apuntalar la asunción del modelo abolicionista en España, sino que también puede desempeñar un papel destacado la forma en que se aplique el delito de trata de seres humanos para explotación sexual, sobre todo en los supuestos de trata abusiva. La doctrina española se ha afanado en buscar interpretaciones restrictivas de medios comisivos como el abuso de una situación de superioridad del tratante o de necesidad o vulnerabilidad de la víctima, con base en una interpretación teleológica del tipo (Villacampa, 2011; Daunis, 2013; Iglesias, 2013), que parece haber asumido el legislador cuando en la reforma de 2015 indica que la situación de 
necesidad o vulnerabilidad debe identificarse con que "la persona en cuestión no tiene otra alternativa, real o aceptable, que someterse al abuso". Pese a ello, el peligro de introducción de un sistema de gestión abolicionista vía trata abusiva sigue acechando, sobre todo cuando en España un relevante sector de la academia viene denunciando la identificación absoluta entre trata y prostitución (Juliano, 2002; Osborne, 2004; Mestre, 2007 y 2019; Maqueda, 2009; Villacampa, 2012; Iglesias, 2012 y 2013; Llobet, 2017).

La confirmación de tal identificación entre trata de seres humanos y prostitución y, con ello, la asunción total del modelo sueco en el ámbito jurídico-penal podría producirse en caso de que llegase a aprobarse el Borrador de proyecto de ley integral contra la trata de seres humanos y en particular con fines de explotación sexual de 2018, formulado para cumplir con los requerimientos del Pacto de Estado contra la violencia de género. Esta propuesta normativa adopta un posicionamiento claramente neoabolicionista, sancionando, conforme al modelo sueco, la compra de servicios sexuales. Así, propone modificar el delito de determinación de adultos a la prostitución del art. 187.1 CP, criminalizando in totum el proxenetismo, convirtiendo en delito el mero lucrarse de la prostitución de otra persona, sin necesidad de explotarla, junto a la incriminación de una versión muy amplia de la tercería locativa y la de la compra de servicios sexuales, que se sanciona con multa con independencia de las condiciones en que se preste la prostitución (Villacampa, 2020). No se plantea tipificar, sin embargo, la incriminación de otras formas de explotación sexual de adultos víctimas de trata, como su uso en espectáculos exhibicionistas o pornográficos o para elaborar material pornográfico, o el consumo de estos servicios.

\section{$4 \quad$ Sanción al trabajo sexual callejero: las ordenanzas cívicas}

Ante la ausencia de regulación del ejercicio de la prostitución a nivel estatal y autonómico más allá de la relevancia jurídico-penal de algunas conductas de facilitación o favorecimiento de la misma, fueron entes locales los que, normando en torno a las ideas del civismo o la convivencia ciudadana en el espacio público, emprendieron una ofensiva contra el trabajo sexual callejero mediante la aprobación de ordenanzas cívicas. Se trataba de normas que incidieron únicamente en el trabajo sexual de calle y que en algunos casos fueron muy contestadas desde sectores de la propia ciudadanía. Aprobadas sobre todo desde los primeros años 2000, establecían los usos correctos del espacio público y sancionaban la realización de conductas contrarias a los mismos. Entre las razones para adoptarlas se apeló a la emergencia de nuevos problemas, aparecidos durante los años anteriores a su aprobación masiva, vinculados al uso vecinal de espacios públicos que carecían de respuesta legal, como el botellón, o a la agravación de problemas tradicionales, como la prostitución callejera (Pemán, 2007; Gracia, 2008). No cabe duda de que la percepción de la inseguridad frente a las conductas incívicas y la asunción por parte del gobierno local de la emisión de normas orientadas a su tutela es común a nuestro país y a otros del occidente europeo, como Italia (Selmini, 2012; Calaresu y Tebaldi, 2015) o Gran Bretaña (Hugues y Edwards, 2005). Sin embargo, en España este proceso se explica además por la paulatina retirada del legislador estatal de las cuestiones relacionadas con el orden público desde los años 90 (Pemán, 2007; Ortega, 2014). En dicho contexto, el refuerzo de la capacidad sancionatoria de los municipios propiciado por la flexibilización del principio de reserva de ley en materia sancionatoria llevada a cabo por la sentencia del Tribunal Constitucional 132/2001 y por la consiguiente reforma de la Ley de Bases de Régimen Local -LBRL(Pemán, 2007; Gracia, 2008; Ortega, 2014) obró el resto (Villacampa, 2015). Tras la referida modificación, en defecto de ley sectorial específica, el Título XI LBRL habilitaba directamente a las ordenanzas locales a tipificar infracciones y sanciones en los ámbitos materiales que enumera su art. 139: las relaciones de convivencia de interés local, el uso de los servicios, equipamientos, infraestructuras e instalaciones locales y el uso del espacio público. 
Con base en dicha habilitación legal, los entes locales comenzaron a adoptar ordenanzas tendentes a barrer el trabajo sexual de la calle. Fue en 2005 cuando Barcelona aprobó la primera de estas ordenanzas municipales, la denominada Ordenanza de medidas para fomentar y garantizar la convivencia en el espacio público, produciéndose una sucesión en la aprobación de este tipo de normas a partir del año 2006, que se han venido adoptando hasta bien entrado el año 2013 (acerca de la sucesión de las aprobadas: Villacampa, 2015; Barcons, 2018).

En muchos casos las ordenanzas aprobadas han seguido el patrón de la barcelonesa, tomada implícitamente como modelo por la Federación Española de Municipios, regulando diversas conductas a realizar en el espacio público. Respecto del ejercicio de la prostitución, este tipo de ordenanzas han sancionado el ofrecimiento, solicitud, negocio o aceptación de servicios sexuales en la vía pública cuando estas prácticas excluyan o limiten la compatibilidad de los diferentes usos del espacio público, así como realizar estas actividades en espacios situados a menos de cierta distancia de centros docentes o educativos, prohibiendo además mantener relaciones sexuales mediante retribución en el espacio público (art. 39 ordenanza cívica de Barcelona). En tanto esta norma, cuyo modelo han seguido otras ordenanzas cívicas, sancionaba conductas de ofrecimiento o negociación de servicios sexuales en la vía pública, estaba sancionando a las propias trabajadoras sexuales. Con ello, instauraba en España lo que se ha denominado como un "modelo prohibicionista suave" (Villacampa y Torres, 2013; Villacampa, 2015) al sancionar administrativamente a las mismas trabajadoras sexuales. Así, a diferencia de los sistemas prohibicionistas puros, como el asumido a nivel estatal en materia de prostitución en Estados Unidos, la trabajadora sexual no era sancionada penalmente, pero sí administrativamente.

La indignación que la aprobación de este tipo de ordenanzas de tenor claramente sancionador para con las trabajadoras sexuales generó entre las asociaciones que las representaban, muestra de la cual es el movimiento "Prostitutas indignadas", que provocó la modificación de la ordenanza cívica barcelonesa para reducir las sanciones aplicables a las trabajadoras sexuales comparativamente con las de los clientes en 2012 (Vartabedian, 2013), también impulsó que se produjese un cambio en la aproximación municipal a esta realidad. Así, junto a este tipo de ordenanzas municipales de corte más sancionatorio, que regularon la prostitución callejera junto a otras conductas incívicas, sancionando a las mismas trabajadoras sexuales, un segundo tipo grupo de municipios adoptaron más modernamente ordenanzas específicamente enderezadas a luchar contra la prostitución (Villacampa, 2015; Barcons, 2018). Un ejemplo de este segundo grupo de municipios nos lo brinda Sevilla, que en 2011 aprobó su ordenanza para luchar contra la prostitución y la trata con fines de explotación sexual en la ciudad de Sevilla. La ordenanza sevillana, adoptando claramente los postulados neoabolicionistas y, con ellos, el modelo sueco, considera la prostitución como una manifestación de la violencia de género, la identifica con la trata de seres humanos. No sanciona la conducta de las personas prostituidas, a las que considera víctimas, sino que se dirige a sancionar la demanda, la conducta de los consumidores de servicios sexuales, y la de quienes favorecen o promueven este tipo de consumo, con acciones como acercar a los clientes a lugares donde se prestan estos servicios o el uso de medios que faciliten el contacto con la persona prostituida, así mediante el uso de panfletos, de carteles o anuncios. Semejantes al contenido de la sevillana son los de otras ordenanzas sobre la cuestión adoptadas más recientemente, como la de Murcia de 23 de septiembre de 2013 o la de Valencia de 26 de julio de 2013.

Cabe, pues, observar la existencia de dos modelos de ordenanzas municipales sobre este particular (Villacampa, 2015). El primero, identificado con la primera fase de la aprobación de ordenanzas cívicas, cuyo principal exponente es la norma barcelonesa, que impone un sistema prohibicionista, que en Cataluña se vio afianzado mediante una modificación de la Ley catalana de Carreteras, que en 2011 impuso sanciones de hasta $30.000 €$ a la realización de usos y actividades relacionados con la prestación de servicios de naturaleza sexual en las carreteras. El segundo grupo de ordenanzas 
asume los postulados del modelo neoabolicionista sueco o nórdico, que busca incidir en la demanda, sancionando al consumidor de servicios sexuales, pero sin sancionar a la trabajadora sexual. Este segundo modelo, que podría considerarse representado por la ordenanza sevillana, es el que parecía podría haberse acabado imponiendo en el ámbito local si no hubiese sido por la aprobación de la Ley Mordaza. En efecto, antes de la aprobación de esta norma de ámbito estatal algún ayuntamiento modificó la correspondiente ordenanza cívica para suprimir las sanciones imponibles a las trabajadoras sexuales, manteniendo solo las de los clientes, iniciando con esto el tránsito desde el prohibicionismo al abolicionismo. Así sucedió en Lleida en enero de 2015 y se intentó en Barcelona, que estaba en proceso de emprender una modificación de este tipo al ganar las elecciones municipales Barcelona en Comú en mayo 2015, aun cuando la misma no llegó a operarse antes de que volviese a cambiar la conformación del gobierno municipal en las últimas elecciones locales.

\section{Más de lo mismo: La Ley Mordaza}

La aprobación de la LO 4/2015 acabó con el vacío legal que había permitido hasta el momento a los ayuntamientos incidir sancionando la práctica del trabajo sexual en la vía pública o la compra de servicios sexuales en la misma. Dicha norma sustituyó a la anterior Ley sobre Protección de la Seguridad Ciudadana que, al no abordar la cuestión de la prostitución, había permitido que los ayuntamientos normasen en la materia ante la ausencia de ley sectorial específica. Con la aprobación de la referida norma sectorial, los ayuntamientos pasan a poder únicamente introducir especificaciones o graduaciones en el cuadro de infracciones y sanciones tipificadas en la ley que sirvan para identificar las conductas o a determinar las sanciones, pero pierden la posibilidad de tipificar infracciones o determinar sanciones, según se desprende los arts. 32 y 41 LO 4/2015 (Villacampa, 2015). Se habilita a los gobiernos locales a que ejerzan con sus ordenanzas las funciones atribuidas a los reglamentos mediante la reserva tradicional o relativa de ley, a que desplieguen lo dispuesto en la ley, pero sin poder innovar. Se produce con la aprobación de la Ley Mordaza un proceso de recentralización en la gestión de la seguridad ciudadana en el espacio público similar al que en su día se produjera en Italia con la aprobación de la Ley 15/1999, que contenía disposiciones en materia de seguridad pública (Melossi y Selmini, 2009; Selmini, 2012), lo que ya se anunció que, como había sucedido en Italia, podía acabar comportando una mayor amplitud en la criminalización de conductas que la que se conseguiría mediante la aplicación exclusiva del Derecho penal (Villacampa, 2015).

Precisamente la existencia de esta norma explica que ayuntamientos como Madrid o Valladolid, que a la sazón estaban en proceso de aprobar sus respectivas ordenanzas reguladoras en este ámbito, suspendiesen este proceso normativo. El paso del tiempo ha confirmado que, efectivamente, nos hallamos ante una disposición que ha supuesto que se retomase por parte del Estado la regulación de la seguridad ciudadana, despojando de tal atribución a la administración local. Así, por ejemplo, en Madrid, tras la inicial paralización de la ordenanza cívica en 2015, el grupo socialista en el consistorio presentó en 2019 una iniciativa para aprobar una normativa de este tipo, que no fructificó porque desde los servicios jurídicos municipales se indicó que existía ya ley sectorial reguladora de la materia.

Al margen del referido proceso de recentralización, pese a que inicialmente hubiese podido parecer que con la LO 4/2015 el legislador español culminaba la recepción del modelo sueco iniciada por algunas de las más recientes ordenanzas municipales dictadas en materia de prostitución, ya justo tras su aprobación se consideró que se trataba solo de apariencia (Villacampa, 2015). En efecto, puesto que dicha norma permite seguir sancionando a las trabajadoras sexuales de calle, como después se verá que ha sucedido, abunda en el mantenimiento de un sistema prohibicionista suave en materia de prostitución callejera en España. 
Respecto de la forma en que la Ley Mordaza tipifica la infracción y sanciona el ofrecimiento de servicios sexuales en la calle, se operó un cambio relevante durante la gestación de la misma. El anteproyecto de dicha norma profundizaba muy claramente en el abordaje prohibicionista en materia de prostitución callejera, endureciendo aún más la ofensiva contra la misma emprendida por la administración local. Sin embargo, finalmente dicho sesgo prohibicionista no fue tan evidente, puesto que, al menos aparentemente, los sujetos a los que principalmente se dirigían las sanciones eran los clientes. El anteproyecto sancionada con multas de hasta $30.000 €$ el ofrecimiento, solicitud, negociación o aceptación de servicios sexuales retribuidos en zonas de tránsito público, en las proximidades de lugares destinados a su uso por menores o cuando estas conductas, por el lugar en que se realizasen, pudiesen generar un riesgo para la seguridad vial, aun cuando se preveía que la conducta no se sancionase cuando la persona infractora fuese víctima de trata de seres humanos y dicho extremo quedase acreditado. Además de la sanción pecuniaria, tanto a la trabajadora sexual como al cliente se les podía imponer la pérdida de la posibilidad de obtener permisos de residencia y trabajo si eran extranjeros ilegales, además de poder expulsarlos del territorio nacional. De ahí que el efecto sancionador extremo de esta regulación proyectada en las trabajadoras sexuales callejeras resultaba evidente (Villacampa, 2015). La dureza de la regulación proyectada fue mitigada sobre todo a resultas de los informes emitidos respecto de la misma por la Secretaría de Estado de asuntos sociales y el Consejo de Estado, que alertaron del efecto multiplicador del riesgo de exclusión social en que tales medidas situarían a las trabajadoras sexuales más desfavorecidas.

El tenor de tales informes, junto al influjo de la entonces reciente resolución del Parlamento europeo de 26 de febrero de 2014, determinaron que la Ley Mordaza asumiese formalmente el modelo neoabolicionista basado en la sanción al cliente, aunque solo parcial y aparentemente, porque existen preceptos de la norma que permiten seguir sancionando a las trabajadoras sexuales que ofrecen sus servicios en la vía pública. Pervive así, oculta tras la supuesta sanción al cliente, la represión a la desobediencia de la trabajadora sexual (Villacampa, 2015; Maqueda, 2017; Barcons, 2018; Bodelón y Becerra, 2018), e incluso la posibilidad de sancionarla por la realización de actos de exhibición obscena.

El art. 36.11 LO 4/2015 considera infracción grave -sancionable con multa mínima de 601 a $10.400 €$, que puede escalar a los $20.000 €$ en caso de reincidencia y a los $30.000 €$ si concurre especial gravedad- la compra de servicios sexuales, esto es, la solicitud o aceptación por el demandante de servicios sexuales retribuidos en zonas de tránsito público, en las proximidades de lugares destinados a su uso por menores, como centros educativos, parques infantiles o espacios de ocio accesibles a menores de edad, o cuando estas conductas, por el lugar en que se realicen, puedan generar un riesgo para la seguridad vial. En relación con los trabajadores sexuales, el mismo precepto indica que los agentes de la autoridad requerirán a las personas que ofrezcan estos servicios para que se abstengan de hacerlo en dichos lugares, informándoles de que la inobservancia de dicho requerimiento podría constituir una infracción de desobediencia sancionable en los mismos términos que la conducta del cliente que solicita dichos servicios según el art. 36.6 Ley Mordaza. Pero es que, además de por la infracción grave, las trabajadoras sexuales que operan en la calle pueden ser, y han venido siendo, sancionadas por la infracción leve consistente en la realización o incitación a la realización de actos que atenten contra la libertad e indemnidad sexual o en ejecutar actos de exhibición obscena, cuando no constituya infracción penal, sancionable con multa de 100 a $600 €$.

\section{Las consecuencias del prohibicionismo soft}

En un contexto normativo como el descrito, en el que, al margen de la sanción penal de algunas conductas de aprovechamiento de la prostitución ajena, se sanciona administrativamente, junto al cliente, a las mismas trabajadoras sexuales, veamos qué efectos ha tenido la implementación de 
este modelo prohibicionista soft en quienes integran ese colectivo. Debe tenerse en cuenta que se aplica únicamente a quienes ofrecen, negocian o aceptan e incluso practican ese tipo de actividades en la vía pública, por lo que solo puede hablarse de los efectos de estas disposiciones sobre el trabajo sexual callejero, no sobre el ejercido en otros contextos espaciales.

Comenzando por los efectos de las ordenanzas cívicas, que son las que inauguraron la asunción de este tipo de aproximación a la prostitución callejera, con no ser muy cuantiosa la investigación existente, puede comenzarse a hablar de un cierto cuerpo de literatura que analiza sus consecuencias sobre las trabajadoras sexuales. Sin embargo, aunque sobre todo a partir de 2010 se evidencia la existencia de diversos análisis a nivel autonómico o local sobre prostitución, en su mayor parte no se centraron en identificar los efectos que la aprobación de las ordenanzas cívicas han tenido en el trabajo sexual. Así, el Ayuntamiento de Sevilla (2013) efectuó un estudio sobre trata, prostitución y otras formas de explotación sexual en dicha ciudad que abordó el estudio sobre la realidad de las mujeres prostituidas con base en 21 entrevistas a trabajadoras sexuales, aunque no se analizó los efectos que la aplicación de la ordenanza sevillana tuvo en quienes prestaban servicios sexuales en el municipio. Tampoco lo hizo un análisis sobre trata y prostitución elaborado en 2014 por el Grupo de Estudio sobre Prostitución de las Islas Baleares, que evaluó la situación poniendo el foco en el proceso migratorio de las mujeres nigerianas a Palma de Mallorca. Tampoco el estudio elaborado por la asociación Aclad en 2015 sobre la situación de la prostitución en Valladolid efectuó tal análisis, pese a monitorear la situación del ejercicio de la prostitución en la ciudad. Ni siquiera el comprensivo estudio, en el sentido de geográficamente extenso, sobre trata de seres humanos para explotación sexual y su relación con la prostitución efectuado por Meneses, Uroz y Rúa para la Delegación del Gobierno para la Violencia de Género (2015), muy focalizado en determinar la relación existente entre las dos realidades mencionadas, abordó la aplicación de tales ordenanzas. Sin embargo, sí se han referido a la implementación de estas normas análisis como el llevado a cabo por el Comité de Apoyo a las Trabajadoras del Sexo en relación con la ordenanza de Murcia (2014) o por la Asociación Pro Derechos Humanos de Andalucía (2015).

En el ámbito académico se han publicado durante el último decenio en Cataluña estudios que analizan específicamente los efectos que ha tenido la aprobación de las ordenanzas cívicas de Barcelona y Lleida sobre las trabajadoras sexuales, acudiendo a muestras de estudio integradas por personas que se dedican a esa actividad. El primero de estos, referido a la ciudad de Barcelona, comenzó a ejecutarse antes de la aprobación de la ordenanza cívica, aunque en la segunda fase de la investigación que lo integró pudo tenerse en cuenta ya el contenido de dicha norma y el efecto que tuvo en las trabajadoras sexuales en un análisis llevado a cabo por Arella, Fernández, Nicolás y Vartabedian (2007). En el mismo se efectuaron 33 entrevistas en profundidad, varias de ellas a trabajadores sexuales, en que se constató cómo las vulneraciones de los derechos humanos sufridas por este colectivo antes de la aprobación de la ordenanza se habían intensificado tras su vigencia. Se confirmó cómo la aprobación de la norma había contribuido a la zonificación del trabajo sexual en la calle mediante la presión policial y la sanción al ofrecimiento de servicios sexuales. También en Barcelona, un posterior estudio cualitativo efectuado con 25 trabajadores sexuales travestidos emigrados desde Brasil permitió confirmar el acoso policial que había provocado la aplicación de la ordenanza de forma incluso más evidente (Vartabedian, 2013).

Ya en 2012 se emprendió un estudio empírico con trabajadores sexuales específicamente orientado a conocer los efectos que la aprobación de la ordenanza municipal en Lleida había tenido sobre este colectivo (Villacampa y Torres, 2013). Mediante el empleo de metodología cuantitativa y cualitativa, consistente en 79 cuestionarios a trabajadores sexuales y entrevistas en profundidad a 20 de ellas, se confirmó que el $66 \%$ de las personas encuestadas consideraron que la aprobación de dicha norma cuatro años antes había tenido efectos en su actividad. Entre ellos, sobre todo, el incremento del control policial (29\%), al que siguieron la disminución de clientes (17\%), la disminución de ingresos 
por servicio (13\%) o la mayor dificultad para negociar con el cliente (11\%). Del estudio se dedujo que la aplicación de la ordenanza no había supuesto modificaciones sustanciales en las condiciones de trabajo de las mujeres integrantes de la muestra, ya de por sí duras, aunque tampoco había sido capaz de disminuir el número de oferta de servicios sexuales en la calle, que se constató que había incrementado en los años inmediatamente anteriores. Lo que sí pudo evidenciarse fue el incremento del control policial como efecto principal de la aprobación de la ordenanza. Las trabajadoras sexuales vincularon claramente la presencia policial al control de su actividad, exponiendo que temían a la policía, en unos casos por la sanción que podían imponerles y en otros por su condición de irregulares. Se confirmó cómo la policía había cambiado su rol, pasando de la actitud protectora del pasado a una posición eminentemente controladora, lo que llevó a las mujeres a desarrollar estrategias de huida ante la presencia policial. Además, se evidenció que, aunque normalmente las multas no se hacían efectivas, se sancionaba más a las mujeres que a los clientes, pues ellas eran advertidas o sancionadas directamente por estar en la calle esperando a algún cliente o por simplemente deambular, mientras que ellos solo eran sancionados cuando se les sorprendía manteniendo relaciones sexuales en la vía pública.

Los resultados de esta primera investigación han sido posteriormente confirmados en otra más reciente orientada a conocer los efectos de este tipo de ordenanzas aprobadas en distintas ciudades catalanas y españolas. Se trata de un análisis cualitativo consistente en la realización de 32 entrevistas, 5 de ellas a trabajadoras sexuales. Concluye también que el principal efecto de este tipo de normativas es la criminalización del trabajo sexual callejero (Barcons, 2018; Bodelón y Becerra, 2018). Destaca cómo, partiendo de datos de la policía local barcelonesa, en 2011 el 100\% de las sanciones se impusieron a trabajadoras sexuales; mientras en 2013 y 2014, alrededor del $60 \%$ de las sanciones se impusieron de nuevo a estas por ofrecer servicios sexuales en la vía pública, recayendo en los clientes entre el 26 y el $29 \%$ de las sanciones por demandar su prestación (Bodelón y Becerra, 2018).

En definitiva, estos estudios confirman lo que ya habían apuntado algunas organizaciones que representan a las trabajadoras sexuales, en el sentido de que las ordenanzas contribuyen a dejar a las mujeres que se dedican a la prostitución callejera sin alternativa. Ponen de manifiesto que se trata de normas que abocan a las trabajadoras sexuales a una situación de ilegalidad, a poder ser sancionadas y a la absurda situación de tener que prestar servicios sexuales para poder hacer frente a las sanciones impuestas, criminalizando la pobreza. Además, permiten poner en duda la efectividad de tales ordenanzas en la disminución de la oferta de trabajo sexual callejero, confirmando que, más que una reducción, lo que se produce es una traslación de estas conductas a entornos menos visibles, que incluso pueden incrementar las condiciones de inseguridad en que estos servicios se prestan. Evidencian cómo se trata, en definitiva, de invisibilizar el ejercicio del trabajo sexual, sin haber conseguido acabar con él.

Aun cuando todavía no han evaluado científicamente los efectos que la aprobación de la Ley Mordaza ha tenido sobre el ejercicio del trabajo sexual, cuando esto se haga seguramente se verá que no han sido demasiado diversos a los de las ordenanzas cívicas, dado que también permite sancionar a las mismas trabajadoras sexuales. Sí puede indicarse, tras cuatro años de vigencia de esta norma, que parece que en lo que a erradicación de la prostitución callejera se refiere, lo mismo que sus predecesoras las ordenanzas municipales, no ha sido demasiado eficiente.

Del mismo modo, los efectos sancionadores de la norma se han hecho notar de nuevo más en las trabajadoras sexuales que en los clientes. Según informaciones periodísticas (El diario, 2018) la policía usa la Ley Mordaza para tramitar una denuncia diaria contra las prostitutas por exhibición obscena. En 2017 se confirmó cómo la policía había presentado desde 2015 más de 1.100 denuncias por realizar actos contra la libertad e indemnidad sexual o de exhibición obscena. En 2017 se impusieron de media 1,3 denuncias diarias contra mujeres por ejercer en la vía pública, aunque no 
consta cuántas fueron multadas. Madrid es la zona del país que más denuncias acumuló en 2016, presentándose más del $50 \%$ de las interpuestas en esta zona del país, seguido por Valencia y Pontevedra (4\%), así como Alicante (3\%), aun cuando sin contarse con datos de Cataluña.

Precisamente fue a propuesta de la Comunidad de Madrid por lo que se previó en la Ley Mordaza la sanción a los clientes de la prostitución. Se pretendía con ello acabar con situaciones como las producidas en Villaverde, en la conocida como Colonia Marconi. Sin embargo, se observa cómo finalmente las destinatarias de las sanciones son nuevamente más las trabajadoras sexuales que los clientes. En puridad, el efecto sancionatorio de la LO 4/2015 sobre los clientes parece que se estancó aproximadamente a los 3 años de entrada en vigor de la norma en unas 550 sanciones al año (El País, 2018). Pese a que se incoaron muchos expedientes sancionatorios contra clientes durante los primeros seis meses de vigencia de la norma, en 2016 llegaron a los 569 y en 2017 hasta los 658, aunque con carácter posterior parece que el número de denuncias se ha reducido.

En conclusión, lo mismo que sus predecesoras las ordenanzas cívicas, que adoptaron una aproximación prohibicionista suave a la prostitución, la Ley Mordaza, que tras la aparente asunción del modelo abolicionista sigue la senda del prohibicionismo soft, no ha ofrecido una solución satisfactoria a la situación de la prostitución en España. Igual que las referidas ordenanzas, focaliza su atención en la prostitución callejera, que pretende invisibilizar, pero sin conseguirlo, pues no se ha evidenciado su eficiencia en la disminución de oferta de servicios sexuales en la vía pública. Junto a ello, ha abundado en la criminalización de las trabajadoras sexuales de calle, a las que sanciona administrativamente y condena a seguir trabajando para poder pagar las sanciones impuestas. Esto con el efecto añadido de que el uso del Derecho administrativo sancionador frente al Derecho penal como herramienta a través de la que articular esta aproximación prohibicionista soft puede ser incluso más perjudicial para las personas sancionadas, puesto que el procedimiento administrativo sancionador contempla menos garantías para el justiciable que el procedimiento penal. Esto hasta el punto de que podemos encontrarnos con que una persona víctima de trata para explotación sexual que sea obligada por el proxeneta a prostituirse en la vía pública pueda acabar sancionada, primero conforme a la ordenanza específica, ahora de acuerdo con la Ley Mordaza, por ofrecer servicios sexuales en la vía pública (Villacampa, 2015). En definitiva, pues, como de lo que se trata con estas normas es de sancionar el ofrecimiento de servicios sexuales en determinados espacios sin analizar en qué condiciones se están prestando, puede perfectamente suceder que personas que están siendo forzadas a prostituirse por traficantes no solo no sean identificadas por el sistema como víctimas de trata, sino, lo que es peor, que acaben siendo sancionadas por aplicación de las sanciones primero previstas por las ordenanzas cívicas y ahora en la Ley Mordaza y, con ello, doblemente victimizadas. De ahí que la aplicación de normas inicialmente aprobadas para acabar con los casos de trata puede finalmente tornarse en potenciadora e invisibilizadora de tales situaciones, $\sin$ articular al mismo tiempo una respuesta normativa holística frente a las diversas manifestaciones de la explotación sexual y sin ofrecer alternativa de ejercicio legal a quienes prestan libremente servicios sexuales.

\section{Reflexiones conclusivas}

En el actual escenario de anomia en materia de prostitución al margen de las disposiciones penales, combinado con una aproximación claramente abolicionista en lo político y prohibicionista soft en lo normativo, articulada primero a través de las ordenanzas cívicas y después por medio de la Ley Mordaza, se ha conseguido incidir únicamente en el trabajo sexual callejero haciendo más complejas e inseguras las condiciones ambientales de su ejercicio.

Tanto los estudios académicos efectuados sobre la implementación de las ordenanzas municipales como las informaciones con que se cuenta respecto de la aplicación de la Ley Mordaza han puesto 
de manifiesto que estas normas han tenido un efecto fundamentalmente represivo sobre las trabajadoras sexuales. No han sido, sin embargo, eficaces en cuanto a la disminución de la oferta de servicios sexuales en la calle, habiéndose reducido su efecto fundamentalmente a aumentar el temor de las trabajadoras sexuales a ser sancionadas por las fuerzas y cuerpos de seguridad, a las que recurren menos en busca de apoyo por el temor a la sanción. Con tal aproximación, como ya advertían las asociaciones que confieren voz a las trabajadoras sexuales, se criminaliza la pobreza, al sancionarse a las trabajadoras sexuales más desfavorecidas, las que prestan sus servicios en la calle.

Atendiendo a la escasa efectividad de ordenanzas cívicas y Ley Mordaza para acabar con la prostitución callejera y a su nulo efecto para mejorar las condiciones vitales de las trabajadoras sexuales en general, parece evidente que el modelo prohibicionista suave centrado exclusivamente en la sanción al trabajo sexual callejero, que impide la detección de situaciones de trata y de prostitución forzada llegando incluso a sancionar a sus víctimas, debería ser definitivamente abandonado. Hecho esto, ciertamente resulta difícil determinar cuál sea el modelo político legislativo más adecuado a adoptar en un tema tan complejo como el que nos ocupa. En todo caso, sí resulta aconsejable que este asunto se aborde a nivel estatal, sin dejarlo en manos de la gobernanza local, y como una cuestión global, sin limitar la intervención normativa a la prostitución callejera, como hasta el momento se ha hecho a golpe de ordenanza cívica y Ley Mordaza. Además, cualquier propuesta normativa debería contar con la opinión de los colectivos afectados. Con todo, resulta difícil tomar posición acerca de que el abordaje deba ser neoabolicionista -sancionando a los compradores de servicios sexuales- o legalizador de prácticas dignas y seguras de trabajo sexual. En mi opinión, el error consiste en considerar que debe necesariamente escogerse una u otra aproximación, cual si se tratase de compartimentos estanco. Ambas opciones no deberían ser excluyentes: podría perfectamente normarse en esta cuestión reconociendo plenitud de derechos sociales a quienes optan voluntariamente por ofrecer este tipo de prestaciones, al mismo tiempo que se sanciona penalmente y con severidad la trata de seres humanos para explotación sexual, la esclavización sexual, el lucro obtenido explotando directa o indirectamente la prostitución coactiva y el consumo de servicios sexuales de personas forzadas a prostituirse o a prestar cualquier otro tipo de servicio de naturaleza sexual. 


\section{Bibliografía}

Arella, C, Fernández, C, Nicolás, G y Vartabedian, J (2007). Los pasos (in) visibles de la prostitución. Estigma, persecución y vulneración de derechos de las trabajadoras sexuales en Barcelona, Barcelona: Virus Editorial.

Asociación Pro Derechos Humanos de Andalucía (2015). Informe sobre la aplicación de las Ordenanzas Municipales para la Convivencia en El Puerto de Santa María. En https://www.apdha.org/aplicacion-de-las-ordenanzas-municipales-para-la-convivencia-en-elpuerto-de-sta-maria/. Último acceso el 8 de junio de 2020.

Ayuntamiento de Sevilla (2013) Estudio sobre la trata, la prostitución y otras formas de explotación sexual en la ciudad de Sevilla. https://www.sevilla.org/servicios/mujer-igualdad/planesmunicipales/plan-integral-contra-la-prostitucion/. Último acceso el 6 de junio de 2020.

Barcons, M (2018). Las ordenanzas municipales: entre la regulación y la sanción de la prostitución en España. Revista Crítica Penal y Poder 15, pp. 90-109.

Beckett, K y Herbert, S (2010). Banished: The New Social Control in Urban America, Oxford, New York: University Press.

Bickford, S (2000). Constructing inequality: City spaces and the architecture of citizenship. Political Theory 28 (3), pp. 355-376.

Bodelón, E y Becerra, P (2018). La reglamentación de la prostitución en los ayuntamientos: una técnica de ficticia seguridad ciudadana. Revista Crítica Penal y Poder 15, pp. 71-89.

Calaresu, M y Tebaldi, M (2015). Local security policies and the protection of territory: an analysis of the italian experience (2007-2009). City, Territory and Architecture 2 (1), pp. 1-18.

Comité de Apoyo a las Trabajadoras del Sexo (2014). Informe septiembre 2014. Evaluación de la Ordenanza para luchar contra la prostitución en el municipio de Murcia. En http://www.asociacioncats.es/publicaciones/. Último acceso el 6 de junio de 2020.

Daunis, A (2013). El delito de trata de seres humanos: el art. 177 bis CP, Valencia: Tirant lo Blanch.

Delegación del Gobierno para la Violencia de Género (2015). Apoyando a las víctimas de trata. Las necesidades de las mujeres víctimas de trata desde la perspectiva de las entidades especializadas y profesionales involucrados. Propuestas para la sensibilización contra la trata. En https://violenciagenero.igualdad.gob.es/violenciaEnCifras/estudios/investigaciones/2015/estudio/ Apoyando Victimas Trata.htm. Último acceso el 10 de junio de 2020.

Delegación del Gobierno para la Violencia de Género (2019). Documento refundido de medidas del Pacto de Estado en materia de violencia de género. Congreso+Senado. En https://violenciagenero.igualdad.gob.es/pactoEstado/docs/Documento Refundido PEVG 2.pdf.

Último acceso el 10 de junio de 2020.

Ekberg, G (2004). The Swedish Law that prohibits the purchase of sexual services. Best practices for prevention of prostitution and trafficking in human beings. Violence Against Women 10, pp. 11871218.

El diario (2018). La policía usa la Ley Mordaza para tramitar una denuncia diaria contra prostitutas por "exhibición obscena". En https://www.eldiario.es/sociedad/denuncia-diaria-ejercenprostitucion-Espana 0 810869767.html. Último acceso el 6 de junio de 2020.

El País (2018). Las sanciones a clientes de prostitutas en Madrid se estancan en unos 550 casos al año. En https://elpais.com/ccaa/2018/08/24/madrid/1535131764 698063.html. Último acceso el 6 de junio de 2020. 
Gracia, R (2008). Convivencia ciudadana, prostitución y potestad sancionadora municipal. El caso de Barcelona. Cuadernos de Derecho Local 17, pp. 99-133.

Hugues, G y Edwards, A (2005). Crime prevention in context, en Tilley, N. Handbook of Crime Prevention and Community Safety, Cullompton, Devon: Willan, pp. 14-34.

Iglesias, A (2012). Políticas públicas de lucha contra la trata de mujeres en el contexto español: luces y sombras, en Iglesias, A y Puente, LM. Sistema penal y perspectiva de género. Trabajo sexual y trata de personas, Granada: Comares, pp. 61-80.

Iglesias, A (2013). Trata de mujeres con fines de explotación sexual, Tirant lo Blanch: Valencia.

Juliano, D (2002). La prostitución: el espejo oscuro. Icaria: Barcelona.

Llobet, M (2017). ¿Prostitución?: ni sí ni no, sino todo lo contrario. Revista Electrónica de Ciencia Penal y Criminología 19, pp. 1-34.

Maqueda, M (2009). Prostitución, feminismos y Derecho penal. Comares: Granada.

Maqueda, M (2015). La criminalización del espacio público: el imparable ascenso de las "clases peligrosas". Revista Electrónica de Ciencia Penal y Criminología 17, pp. 1-56.

Maqueda, M (2017). La prostitución: el "pecado" de las mujeres. Cuadernos Electrónicos de Filosofía del Derecho 35, pp. 64-89.

Melossi, D y Selmini, R (2009). Modernisation of institutions of social and penal control in Europe: The "new" crime prevention, en Crawford, A. Crime Prevention Policies in Comparative Perspective, Cullopton, Devon: Willan, pp. 153-176.

Mestre, R (2007). Trabajo sexual, igualdad y reconocimiento de derechos, en Serra, R. Prostitución y trata: marco jurídico y régimen de derechos, Valencia: Tirant lo Blanch, pp. 13-42.

Mestre, $R$ (2019). Apuntes rápidos sobre reducciones, confusiones y otras manipulaciones en torno a la trata de seres humanos, en Rodríguez, B. Autonomía, género y derecho: debates en torno al cuerpo de las mujeres, Valencia: Tirant lo Blanch, pp. 161-172.

Ortega, J (2014). Derechos fundamentales y ordenanzas locales. Madrid: Marcial Pons.

Osborne, R (2004). Introducción, en Osborne, R. Trabajador@s del sexo. Derechos, migraciones y tráfico en el s. XXI, Barcelona: Edicions Bellaterra, pp. 19-42.

Pemán, J (2007). Ordenanzas municipales y convivencia ciudadana: reflexiones a propósito de la Ordenanza de civismo de Barcelona. Revista de Estudios de la Administración Local y Autonómica 35, pp. 9-55.p

Selmini, R (2012). Social crime prevention in Italy: A never ending story, en Hebberecht, P y Baillergeau, E. Social Crime Prevention in Late Modern Europe. A comparative perspective, Brussels: VUB Press, pp. 209-233.

Sobrino, C (2018). Prostitución callejera y regulación jurídica española. Estado de la cuestión. Indret 4, pp. 1-31.

Vartabedian, J (2011). Trabajo sexual en Barcelona. Sobre la gestión municipal del espacio público. Oñati Socio-legal Series 1 (2), pp. 1-13.

Vartabedian, J (2013). "Tengo mucho placer para enseñarte": sobre travestis brasileñas trabajadoras del sexo y la gestión pública de la prostitución en Barcelona. Quaderns-e Institut Català d'Antropologia 18 (1), pp. 80-97. 
Villacampa, C (2011). El delito de trata de seres humanos. Una incriminación dictada desde el Derecho internacional, Cizur Menor: Thomson Reuters-Aranzadi.

Villacampa, C (2012). Políticas de criminalización de la prostitución: análisis crítico de su fundamentación y resultados. Revista de Derecho Penal y Criminología 7, pp. 81-142.

Villacampa, C (2015). A vueltas con la prostitución callejera: ¿hemos abandonado definitivamente el prohibicionismo suave?. Estudios Penales y Criminológicos 35, pp. 413-455.

Villacampa, C (2020). ¿Es necesaria una Ley integral contra la trata de seres humanos?. Revista General de Derecho Penal 33, pp. 1-57.

Villacampa. C y Torres, N (2013). Políticas criminalizadoras de la prostitución en España. Efectos sobre las trabajadoras sexuales. Revista Electrónica de Ciencia Penal y Criminología 15, pp. 1-40.

Wacquant, L (2009). Punishing the Poor: The Neoliberal Government of Social Insecurity. Durham, NC: Duke University Press. 